\title{
Dempster-Shafer 理論における巨視的な情報測度についで
}

\author{
乾口雅 弘 $^{* *}$. 前川 裕*** 一 久米靖 文 $^{* *}$
}

On a Global Measure of Information in Dempster and Shafer's Theory*

Masahiro InUiguchi ${ }^{* *}$, Yutaka MAEKAWA ${ }^{* *}$ and Yasuf umi KumE**

\begin{abstract}
Two types of ambiguity are recognizable in Dempster and Shafer's theory of evidence. One is the ambiguity of the system itself and the other is the ambiguity of human knowledge or information about the system. In this paper, from this point of view, the property for measuring the ambiguity of the system and the property for measuring the ambiguity of human knowledge or information are discussed. A global measure of information which satisfies both of these properties is proposed. The unicity of the proposed measure is proved when it must be an extension of Shannon entropy: The soundness of this measure of information is confirmed by a simple experiment.
\end{abstract}

\section{1.はじめに}

近年, Shannon のエントロピーに代表される情報 測度の概念が，ファジィ集合理論 ${ }^{1)}$, 可能性理論 ${ }^{2)}$, Dempster と Shafer の証拠理論尚,4) 亿導入され, 種々 の情報測度 ${ }^{5) \sim 8)}$ が提案されている. Klir ら ${ }^{5), 6)}$ は, 不確 かさ (uncertainty) の様相を分類し, 種々の情報測度 を位置付け，それらの基礎となる理論を示している。 こ れらの情報測度は, 従来の確率理論に抢ける種々のエン トロピー9) とは異なり, 不確かさのさまざまな局面を捕 らえている.

確率論の拡張である Dempster と Shafer の証拠理 論は, 不確かさ (uncertainty) のうち不明確さ (ambiguity) を扱う理論であり ${ }^{5)}$, 不明確さの三つの局面を表 わす, 不一致, 混述, 不特定仼関する情報測度 ${ }^{5) \sim 8)}$ が提 案されている. てれらの測度は, 不明確さの各局面をう まく表現しているが, 全体的な意味での不明確さを表わ す測度としては適当ではない. したがって, 全体的な不 明確さを比較する場合, これらの測度を単独で用いるこ

* 原稿受付 1990. 8. 28

** 大阪府立大学 土学部 University of Osaka Prefecture, College of Engineering ; Mozu-Umemachi, Sakai 591, JAPAN

*** ミノルタカメラ情報システム部 Minolta Camera Co., Ltd. ; Azuchimachi, Chuo-ku, Osaka 541, JAPAN

Key Words : measure of information, Dempster and Shafer's theory of evidence, ambiguity, body of evidence, global measure of information.
とは妥当ではない：また，乙れらの測度の複数個を用い， ベクトル値として評価しても, 半順序構造をひきおこし, 比較不可能となる場合が多い.

Lamata と Moral ${ }^{8)}$ は, 全体的な不明確さを表わす 情報測度（以後, 巨視的な情報測度と呼ぶ）として, 下 界エントロピー, 上界エントロピーと呼ばれる二つの測 度を提案している. てれらの測度は, 不一致と不特定を 表わす情報測度の和として定義されている. また, 彼ら は巨視的な情報測度が満たすべき四つの性質を掲げてい る. 下界エントロピー, 上界エントロピーは, てれらの 性質を満足しているが, 不一致と不特定を表わす情報測 度の和として定義されなければならない理由が明らかで はない。

証拠理論が確率論と異なる点は, 無知量が扱えるとと である.したがって, 証拠理論では, 確率論で主として 扱う対象とする系 (システム) 自体に内在する不明確さ に加えて, 人間の系に対する知識, 情報における不明確 さをあ扱っていると考えられる. 後に述べるように，系 自体の不明確さは不一致の測度に関係し, 人間の知識,

情報における不明確さは不特定の測度に関係している.

本研究では, 証拠理論において, 対象とする系自体の 不明確さと, 人間の系に対する知識, 情報の不明確さが 取り扱われているという考え方に基づき，新たな巨視的 な情報測度を提案する. また, 提案された情報測度の性 質を吟味する. 最後に, 簡単な実験により, 提案されだ 巨視的な情報測度の妥当性を検討する. 


\section{2. 証拠理論における種々の情報測度}

\subsection{Dempster と Shafer の証拠理論}

Dempster とShafer の証拠理論 ${ }^{3), 4)}$ では, 通常の確 率に適さない主観にかかわる不確実性を扱うため，全体 集合の各要素にではなく，部分集合に確率を割り当てて いる．各部分集合に割り当てる確率を定める関数 $m$ : $\mathscr{P}(X) \rightarrow[0,1]$ は, 基本割当てと呼ばれ, 次の条件 ( i ) 〜 (iii ) を満足する.

(i) $0 \leqq m(A) \leqq 1, A \subseteq X$

(ii) $m(\phi)=0, \phi$ は空集合である.

(iii) $\sum_{A \subseteq X} m(A)=1$

ただし, $\mathscr{Q}(X)$ は $X$ のべき集合である. $m(A)$ は $X$ の部分集合 $A$ に割り当てられた確率を示し，A内の各 点を自由に動ける半可動確率質量と考えられている ${ }^{3)}$, . $m(A)>0$ なる $X$ の部分集合 $A$ を焦点要素と呼び，そ の集合を $\mathscr{I}$ と記す．焦点要素の集合 $\mathscr{I}$ と基本割当て $m$ の対 $(\mathscr{F}, m)$ を証拠の体と呼ぶ，とくに，すべての 焦点要素 $A$ が単集合であるとき, $(\mathscr{F}, m)$ は通常の確 率分布を表わす。なお， $X=\left\{x_{1}, x_{2}, \cdots, x_{n}\right\}$ と仮定し ている.

証拠の体 $(\mathscr{F}, m)$ が与えられると, belief 測度 (Bel), plausibility 測度 $(\mathrm{Pl})$ は，次のように定義される.

$$
\begin{aligned}
& \operatorname{Bel}(A)=\sum_{B \subseteq A} m(B) \\
& \operatorname{Pl}(A)=\sum_{B \cap A \neq \phi} m(B)
\end{aligned}
$$

明らかに,

$$
\operatorname{Bel}(A) \leqq \operatorname{Pl}(A), \quad{ }^{\mathrm{V}} A \subseteq X
$$

が成立する. とくに，焦点要素がすべて単集合である， すなわち，( $\mathscr{I}, m)$ が通常の確率分布を表わすとき，

$$
\operatorname{Pr}(A)=\operatorname{Bel}(A)=\operatorname{Pl}(A),{ }^{\forall} A \subseteq X
$$

となる。ただし， $\operatorname{Pr}(A)$ は $A$ の確率測度である.

いま，直積空間 $X \times Y$ 上に証拠の体 $(\boldsymbol{I}, m)$ が与え られたとする.すなわち，基本割当て $m$ は，

$$
m: \mathscr{P}(X \times Y) \rightarrow[0,1]
$$

となる. また, 各焦点要素は $X \times Y$ 上の二項関係 $R$ と なる. $R$ の $X, Y$ への射影をそれぞれ， $R_{x}, R_{y}$ とする と.

$$
\begin{aligned}
& R_{x}=\left\{\left.x \in X\right|^{\exists} y,(x, y) \in R\right\} \\
& R_{y}=\left\{\left.y \in Y\right|^{\exists} x,(x, y) \in R\right\}
\end{aligned}
$$

と書ける. このとき， $m$ の $X, Y$ への射影をそれぞれ 次のように定義できる.

$$
\begin{aligned}
& m_{x}(A)=\sum_{R: A=R_{x}} m(R),{ }^{\forall} A \subseteq X \\
& m_{y}(B)=\sum_{R}: \sum_{B=R_{y}} m(R), \quad{ }^{\forall} B \subseteq Y
\end{aligned}
$$

$m_{x}, m_{y}$ は周辺基本割当てと呼ばれ，それらに付随する

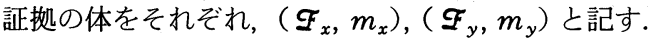

${ }^{\forall} A \in \mathscr{F}_{x},{ }^{\forall} B \in \mathscr{F}_{y}$ について

$$
\begin{aligned}
& m(A \times B)=m_{x}(A) \cdot m_{y}(B) \\
& m(R)=0,{ }^{\forall} R \neq A \times B
\end{aligned}
$$

が成立するとき， $\left(\mathscr{F}_{x}, m_{x}\right)$ と $\left(\mathscr{F}_{y}, m_{y}\right)$ には，乗算に 関して相互関係がないという。

“P は犬である”.という証拠は“ $P$ は動物である” と いう証拠を含んでいる。乙のような証拠の包含関係を Delgadoと Moral ${ }^{10)}$ は，次のように証拠理論の枠組 みに表現している.

すなわち， $X$ 上の二つの証拠の体 $\left(\mathscr{F}_{1}, m_{1}\right),\left(\mathscr{F}_{2}, m_{2}\right)$ が与えられたとする. このとき，任意の $A \subseteq X$ につい $\tau$

$$
\begin{aligned}
& m_{1}(A)=\sum_{B: B \subseteq A} t_{A}(B),{ }^{V} A \subseteq X \\
& m_{2}(B)=\sum_{A}: \sum_{B \subseteq A} t_{A}(B),{ }^{V} B \subseteq X
\end{aligned}
$$

なる写像 $t_{A}: \mathscr{P}(A) \rightarrow[0,1]$ が存在すれば, $\left(\mathscr{F}_{1}, m_{1}\right)$ は $\left(\mathscr{F}_{2}, m_{2}\right)$ に含まれるといい, $\left(\mathscr{I}_{1}, m_{1}\right) \subseteq\left(\mathscr{F}_{2}, m_{2}\right)$ 亡記す.

Delgado と Moral ${ }^{10)}$ は，証拠の体を情報として捕 え，包含関係を上述のように定義したが，Dubois と Prade $^{11)}$ は，証拠の体を集合として捕え，上述の定義 と等価な包含関係を定義している．ただし，Dubois と Prade は集合として証拠の体を捕えているため，上述 の定義とは包含関係の向きが異なっている.

(12)，(13）式の意味を明らかにするため， $\left(\mathscr{F}_{1}, m_{1}\right) \subseteq$ $\left(\mathscr{F}_{2}, m_{2}\right)$ が成立する次の例を考える.

(例 1) $X=\left\{x_{1}, x_{2}, x_{3}, x_{4}\right\}$ 上の二つの証拠の体 $\left(\mathscr{I}_{1}\right.$, $\left.m_{1}\right),\left(\boldsymbol{F}_{2}, m_{2}\right)$ を考える.

$$
\begin{aligned}
& \mathscr{F}_{1}=\left\{A_{1}, A_{2}, A_{3}, A_{4}\right\} \\
& m_{1}\left(A_{1}\right)=0.3, m_{1}\left(A_{2}\right)=0.2, m_{1}\left(A_{3}\right)=0.1 \\
& m_{1}\left(A_{4}\right)=0.4 \\
& A_{1}=\left\{x_{1}, x_{2}, x_{3}, x_{4}\right\}, A_{2}=\left\{x_{2}, x_{3}, x_{4}\right\} \\
& A_{3}=\left\{x_{1}, x_{2}\right\}, A_{4}=\left\{x_{2}, x_{3}\right\} \\
& \mathcal{F}_{2}=\left\{B_{1}, B_{2}, B_{3}, B_{4}, B_{5}, B_{6}\right\} \\
& m_{2}\left(B_{1}\right)=0.2, m_{2}\left(B_{2}\right)=0.2, m_{2}\left(B_{3}\right)=0.2 \\
& m_{2}\left(B_{4}\right)=0.1, m_{2}\left(B_{5}\right)=0.2, m_{2}\left(B_{6}\right)=0.1 \\
& B_{1}=\left\{x_{1}, x_{3}, x_{4}\right\}, B_{2}=\left\{x_{3}, x_{4}\right\}, B_{3}=\left\{x_{2}, x_{3}\right\} \\
& B_{4}=\left\{x_{3}\right\}, B_{5}=\left\{x_{2}\right\}, B_{6}=\left\{x_{1}\right\}
\end{aligned}
$$

乙のとき, $t_{A_{1}}, t_{A_{2}}, t_{A_{3}}, t_{A_{4}}$ を次のように定義すれば, (12)，(13）式を満足するので, $\left(\mathscr{F}_{1}, m_{1}\right) \subseteq\left(\mathscr{F}_{2}, m_{2}\right)$ が 
成立する.

$$
\begin{aligned}
& t_{A_{1}}\left(B_{1}\right)=0.2, t_{A_{1}}\left(B_{2}\right)=0.1 \\
& t_{A_{1}}(B)=0,{ }^{\vee} B \neq B_{1}, B_{2} \\
& t_{A_{2}}\left(B_{2}\right)=0.1, t_{A_{2}}\left(B_{5}\right)=0.1 \\
& t_{A_{2}}(B)=0,{ }^{\vee} B \neq B_{2}, B_{5} \\
& t_{A_{3}}\left(B_{6}\right)=0.1, t_{A_{3}}(B)=0,{ }^{\vee} B \neq B_{6} \\
& t_{A_{4}}\left(B_{3}\right)=0.2, t_{A_{4}}\left(B_{4}\right)=0.1, t_{A_{4}}\left(B_{5}\right)=0.1 \\
& t_{A_{4}}(B)=0,{ }^{\vee} B \neq B_{3}, B_{4}, B_{5}
\end{aligned}
$$

\section{2 種々の情報測度}

Dempster と Shafer の証拠理論を基に，不明確さを 示す測度として，種々の情報測度が提案されている ${ }^{5) ~ 8) . ~}$ こてでは，不一致，混述，不特定の測度について述べ, その後に，巨視的な情報測度である下界エントロピー, 上界エントロピーについて述べる.

不一致の測度：与えられた証拠の体 $(\mathscr{F}, m)$ に対し て, 不一致の測度は次式で定義される゙。

$$
E(m)=-\sum_{A \subseteq X} m(A) \log _{2} \operatorname{Pl}(A)
$$

$E(m)$ は，すべての焦点要素 $A, B \in \mathscr{F}$ に対して $A \cap$ $B \neq \phi$ であるとき, かつまたそのときに限り, 最小値 0 を与える. また， $(\mathscr{I}, m)$ が二様な確率分布を表わす， すなわち, $m\left(\left\{x_{i}\right\}\right)=1 / n,{ }^{\nabla} x_{i} \in X$ となるとき, かつ またそのときに限り, $E(m)=\log _{2}|X|=\log _{2} n$ とな り, $E(m)$ の最大值を与える. ただし, $|X|$ は $X$ の濃 度を示し, $|X|=n$ である.

不一致の測度は，本質的な矛盾の測度と屯考光られて いる8.

混述の測度：与えられた証拠の体 $(\mathscr{F}, m)$ に対して, 混述の測度は次式で定義される。

$$
C(m)=-\sum_{A \subseteq X} m(A) \log _{2} \operatorname{Bel}(A)
$$

$C(m)$ は, 一つの焦点要素 $A \subseteq X$ に対して $m(A)=$ 1 かつ $A$ 以外のすべての $B \subseteq X$ に対して $m(B)=0$ となるとき，かつまたそのときに限り，最小値 0 を与え る. また，すべての焦点要素が他のいずれの焦点要素に あ含まれないようにできるだけ多くの焦点要素をもつ $\mathscr{I}$ を構成し, 各焦点要素に一様に基本確率を割り当て るとき, $C(m)$ は最大值 $\log _{2}\left(\begin{array}{c}n \\ {[n / 2]}\end{array}\right)$ をとる. ただし， [ ] はガウス記号である.

不特定の測度：与えられた証拠の体 $(\boldsymbol{T}, m)$ に対し て, 不特定の測度は次式で定義される.

$$
V(m)=\sum_{A \subseteq X} m(A) \log _{2}|A|
$$

$V(m)$ は，すべての焦点要素が単集合，つまり，( $m$ ）が通常の確率分布を表わすとき，最小值 0 を与え，
$m(X)=1$ で, 任意の $A \subset X$ に対して $m(A)=0$ であ る, つまり, 完全に無知であるとき, 最大値 $\log _{2}|X|=$ $\log _{2} n$ を与える.

不特定の測度は，不精密の測度とも呼ばれている ${ }^{7), 8)}$. 以上，三つの情報測度のうち，不一致，混述の測度は， Shannonのエントロピー

$$
H(p)=-\sum_{i=1}^{n} p_{i} \log p_{i}
$$

の拡張となっている. すなわち, $(\mathscr{F}, m)$ が通常の確率 分布を表わすとき, $E(m) ; C(m)$ は Shannon のエン トロピーと一致する。なお, $p=\left(p_{1}, p_{2}, \cdots, p_{n}\right)$ であ り, $p_{i}$ は $x_{i} \in X$ に割り当てられた確率を示している.

つぎに，巨視的な情報測度である下界エントロピー， 上界エントロピーについて述べる. Lamata と $\mathrm{Moral}^{8)}$ は，系の不明確さは本質的な矛盾（不一致）と不精密さ （不特定さ）に起因していると考え, 不一致と不特定の二 つの不明確さの局面を包括した次の二種類の測度を提案 している.

下界エントロピー

$$
\begin{aligned}
L(m) & =-\sum_{A \subseteq X} m(A) \log _{2} \frac{\operatorname{Pl}(A)}{|A|} \\
& =E(m)+V(m)
\end{aligned}
$$

上界エントロピー

$$
\begin{aligned}
U(m) & =E V_{\mathrm{Bel}}(f) \\
= & \int_{0}^{\infty} \operatorname{Bel}(\{x \in X \mid f(x) \geqq s\}) d s \\
= & E V_{\mathrm{Bel}}\left(-\log _{2} \mathrm{Pl}(\{x\})\right)+\log _{2}\left(\sum_{b \in X} \operatorname{Pl}(\{b\})\right)
\end{aligned}
$$

ただし，

$$
f(a)=\log _{2} \frac{\operatorname{Pl}(\{a\})}{\sum_{b \in X} \operatorname{Pl}(\{b\})}
$$

である.

下界エントロピーと上界エントロピーについて

$$
L(m) \leqq U(m)
$$

が常に成立する.

（18）式より明らかなように，下界エントロピーは不 一致の測度と不特定の測度の和で構成されている. また, $E V_{\mathrm{Bel}}\left(-\log _{2} \mathrm{Pl}(\{x\})\right)$ は不一致の測度之同様な性質を 屯ち, $\log _{2}\left(\sum_{b \in X} \mathrm{Pl}(\{b\})\right)$ は不特定の測度之同様な性質 をあつので, 上界エントロピーも，不一致を表わす測度 と不特定を表わす測度の和として構成されている。

Lamata と Moral は, $L(m)$ と $U(m)$ の性質を基 に，巨視的な情報測度が満たすべき性質として，次の四 つをあげている.

(i ) $m\left(\left\{x_{i}^{\prime}\right\}\right)=1$ なる $x_{i} \in X$ が存在するときに限り

$\dagger 0 \cdot \log _{2} 0=0$ と規約する. 


$$
0 \text { となる. }
$$

(ii ) $(\boldsymbol{I}, m)$ が通常の確率分布を表わすとき, Shannon のエントロピーに一致する.

（iii）乗算に関して相互関係がないとき，加法的であ る.

（iv）本質的な矛盾（不一致）の測度と不精密（不特 定）の測度から構成される。

ここで, 性質（iiii）は，情報測度を $G$ するとき，(10)， (11) 式が成立すれば, $G(m)=G\left(m_{x}\right)+G\left(m_{y}\right)$ とな ることを意味している.

あちろん，下界エントロピーも上界エントロピーあて の四つの性質を満たしている.

\section{3. 新たな巨視的な情報測度の提案}

\section{1 巨視的な情報測度について}

不一致，混述，不特定の情報測度は，不明確さの各局 面をうまく表現しているが, 全体的な意味での不明確さ を表わす測度としては適当ではない，また，下界エント ロピー, 上界エントロピーは, 前章で述べた四つの性質 を満たしているが, 不一致と不特定の情報測度の和とし て定義されなければならない理由が明らかでない，そて で，本章では，証拠理論に押いて扱われている不明確さ について考察し，巨視的な情報測度が満たすべき性質を 導くことにより，新たな巨視的な情報测度を提案する。

証拠理論が確率論と異なる点は, 無知量が扱えるとと である.ししたがって, 証拠理論では, 確率論で主として 扱う，対象之する系自体に内在する不明確さに加えて, 人間の系に対する知識，情報における不明確さをあ扱っ ていると考えられる. 次の例を考えよう.

（例 2 ）袋の中に青紫, 紫, 赤紫, 臙脂, 赤, 朱色, 橙色，柿色，オレンジの玉がいくつか入っている. いま, 紫系 0.2 , 赤系 0.5 , オレンジ系 0.3 の割合で入ってい るという情報を得た. このとき, 袋から玉を一つ取り出 す場合に各色の出る確率は, 次の証拠の体 $(\mathscr{I}, m)$ を 用いて表現される.

$$
\begin{aligned}
& \mathcal{F}=\left\{A_{1}, A_{2}, A_{3}\right\} \\
& m\left(A_{1}\right)=0.2, m\left(A_{2}\right)=0.5, m\left(A_{3}\right)=0.3 \\
& A_{1}=\{\text { 青紫, 紫, 赤紫 }\} \\
& A_{2}=\{\text { 赤紫, 䏚脂, 赤, 朱色 }\} \\
& A_{3}=\{\text { 朱色, 橙色, 柿色, オレンシ }\}
\end{aligned}
$$

こてで， $A_{1}, A_{2}, A_{3}$ はそれぞれ，紫系，赤系，オレン ジ系澹属すると考えら扎る色の集合を表わしている.

乙の例において, 紫系 0.2 , 赤系 0.5 , オレンジ系 0.3 という割合は，玉を一つ取り出す場合に，常にある色の 玉が出るといった確定的な系でないとと，すなわち，系 自体が不明確さを伴っていることを表わしている，一方,
紫系, 赤系, オレンジ系という言葉に対する色が複数個 存在するのは, 紫系, 赤系, オレンジ系という情報ある いは知識における不明確さを表わしている．てのように， 証拠理論では，系自体の不明確さと知識，情報における 不明確さが扱われていると考えられる.

そこで, 本研究では, Lamata之 Moral があげた四 つの性質のうち, 性質 (iv) を

（iv'）系自体に内在する不明確さを表わす情報測度の 性質と, 知識, 情報に押ける不明確さを表わす 情報測度の性質をむつ。

亿置き換え，性質（i ）（iii）および（iv'）を満たす巨 視的な情報測度を提案する．まず，系自体に内在する不 明確さを表現するために満たすべき情報測度の性質，お よび，知識，情報における不明確さを表現するために満 たすべき情報測度の性質を議論する.

\section{2 系自体の不明確さを表わす情報測度の性質}

証拠の体 $(\mathscr{I}, m)$ が与えられたとき，乙の証拠に反し ない確率分布の集合 $\mathcal{E}$ を次のように構成することがで きる.

$$
\begin{aligned}
\mathcal{E}= & \left\{p=\left(p_{1}, p_{2}, \cdots, p_{n}\right) / p_{i}=\sum_{j=1}^{\ell} \chi_{i j} p_{i j},\right. \\
& \sum_{i=1}^{n} \chi_{i j} p_{i j}=m\left(A_{j}\right), p_{i j} \geqq 0, i=1,2, \cdots, n, \\
& j=1,2, \cdots, \ell\} .
\end{aligned}
$$

ただし， $X=\left\{x_{1}, x_{2}, \cdots, x_{n}\right\}$ であり， $p_{i}$ は $x_{i}$ に対する 確率である. また, $\ell$ は焦点要素の数であり, $A_{j}$ は焦 点要素である. さらに, $\chi_{i j}$ は次式で定義される.

$$
\chi_{i j}=\left\{\begin{array}{l}
1 ; x_{i} \in A_{j} \\
0 ; x_{i} \notin A_{j}
\end{array}\right.
$$

対象とする系自体が不明確である場合，系自体はある 確率分布に従っていると考えるのが自然であるう.乙 の考え方基づくと, 確率分布の集合 $\mathcal{E}$ は証拠の体 $(\mathscr{F}, m)$ より考えられる系自体の確率分布の集合であり, $(\mathscr{F}, m)$ が正しい証拠であるとき， $\mathcal{E}$ の中に系自体を表 わす真の確率分布があると考えられる。 な报，本研究で は, $(\mathscr{T}, m)$ は正しい証拠であると考えることにする.

乙の観点から明らかに, 系自体を表わす真の確率分布 の不明確さは, $\mathcal{E}$ 内の確率分布の不明確さの最小值以 上, 最大值以下となるので, $(\mathscr{I}, m)$ によって与えられ る系自体の不明確さむ， $\boldsymbol{E}$ 内の確率分布の不明確さの 最小值以上, 最大值以下となるべきであろう。したがっ て, $p \in \mathcal{E}$ なる任意の確率分布 $p$ に対する証拠の体を $\left(\mathscr{F}_{p}, m_{p}\right)$ とすると, 情報測度 $G(m)$ が系自体の不明 確さを表わすためには，

$$
\min _{p \in \mathcal{E}} G\left(m_{p}\right) \leqq G(m) \leqq \max _{p \in \mathcal{E}} G\left(m_{p}\right)
$$


を満足すべきであろう.

こてで, 不一致の測度 $E(m)$ との関連について述へ る. 不一致の測度 $E(m)$ は，系自体の不明確さを表わ す測度ではない，実際，E $E(m)$ につて (24) 式は成立 せず,

$$
E(m) \leqq \min _{p \in \mathcal{E}} E\left(m_{p}\right)=\min _{p \in \mathcal{E}} H(p)
$$

が成立する. (25) 式は, $E(m)$ が $\mathcal{E}$ 内の任意の確率分 布の不明確さ以下であることを示している。不一致の測 度は，各焦点要素間の排反性が大きいほど大きくなる測 度である ${ }^{5) \sim 7)}$ 乙とから，( $(\boldsymbol{I}, m)$ に対する不一致度は， $\mathcal{E}$ 内の任意の確率分布の不一致度以下でなければなら ない，乙のように，不一致の測度は系自体の不明確さを 表わす測度ではない。しかし, 系自体の不明確さが増す, すなわち，確定的な系から遠ざかり，一様分布に近づく ほど，各焦点要素間の排反性が大きくなると考えられる ので, 不一致の測度は系自体の不明確さに関連している.

上界エントロピー $U(m)$ の定義に用いられている $E V_{\mathrm{Bel}}\left(-\log _{2} \mathrm{Pl}(\{x\})\right)$ についても, 同様なととがいえ る.

\section{3 知識，情報の不明確さを表わす情報測度 の性質}

前章で述べた証拠の体の包含関係 $\left(\mathscr{F}_{1}, m_{1}\right) \subseteq\left(\mathscr{F}_{2}\right.$, $\left.m_{2}\right)$ が成立するとき, 証拠 $\left(\mathscr{F}_{2}, m_{2}\right)$ は証拠 $\left(\mathscr{F}_{1}, m_{1}\right)$ より詳細であるといえる. 知識, 情報における不明確さ の観点から，より詳細な証拠を得るてとによって不明確 さが増すととは不自然である. したがって, 知識, 情報 における不明確さを表わす情報測度 $G(m)$ は，

$$
\begin{array}{r}
\left(\mathscr{F}_{1}, m_{1}\right) \subseteq\left(\mathscr{F}_{2}, m_{2}\right) \text { ならば, } \\
G\left(m_{1}\right) \geqq G\left(m_{2}\right)
\end{array}
$$

を満たすべきであろう.

不特定の測度 $V(m)$ に対して, (26) 式が成立する したがって, $V(m)$ は, 知識, 情報に扔ける不明確さ を表わす測度である.

\section{4 巨視的な情報測度の提案とその性質}

巨視的な情報測度が性質（iv'）を満たすためには, （24）式と（26）式を同時に満たさなければならない. （24），(26）式を同時に満たす情報測度は，次の性質をあ ว,

【命題 1】情報測度 $G(m)$ が (24)，(26）式を満足す るとき，任意の証拠の体 $(\boldsymbol{I}, m)$ について,

$$
G(m)=\max _{p \in \varepsilon} G\left(m_{p}\right)
$$

が成立する.

命題 1 を証明する前に, 次の補題を示す.

【補題 1】 $p \in \mathcal{E}$ なる任意の $p$ 亿対する証拠の体
$\left(\mathscr{F}_{p}, m_{p}\right)$ について, $(\mathscr{F}, m) \subseteq\left(\mathscr{F}_{p}, m_{p}\right)$ が成立する. (証明) $p=\left(p_{1}, p_{2}, \cdots, p_{n}\right)$ とすると, $m_{p}\left(\left\{x_{i}\right\}\right)=$ $p_{i}, i=1,2, \cdots, n, m_{p}(B)=0,{ }^{\forall} B \subseteq X,|B| \neq 1$ が成 立する. また, $\mathcal{E}, \chi_{i j}$ の定義より,

$$
\begin{aligned}
& p_{i}=\sum_{j: x_{j} \in A_{j}} p_{i j}, \quad i=1,2, \cdots, n \\
& m\left(A_{j}\right)=\sum_{i: x_{i} \in A_{j}} p_{i j}, \quad j=1,2, \cdots, \ell \\
& p_{i j} \geqq 0, \quad i=1,2, \cdots, n, \quad j=1,2, \cdots, \ell
\end{aligned}
$$

が成立する. そこで, 任意の $A, B \subseteq X$ について,

$$
t_{A}(B)=\left\{\begin{aligned}
& p_{i j} ; B=\left\{x_{i}\right\}, A=A_{j} \\
& 0 ; \text { その他 }
\end{aligned}\right.
$$

と定義すると，明らかに，

$$
\begin{aligned}
& m(A)=\sum_{B: B \subseteq A} t_{A}(B),{ }^{\forall} A \subseteq X \\
& m_{p}(B)=\sum_{A: B \subseteq A} t_{A}(B),{ }^{\forall} B \subseteq X
\end{aligned}
$$

が成立する。

(証明終)

さて, 命題 1 を証明しよう.

(命題 1 の証明) $\left(\mathscr{F}_{p}^{*}, m_{p}^{*}\right)$ を

$$
G\left(m_{p}^{*}\right)=\max _{p \in \mathcal{E}} G\left(m_{p}\right)
$$

を満たし，確率分布 $p^{*} \in \mathcal{E}$ を表わす証拠の体とする. 乙のとき, $p^{*} \in \mathcal{E}$ であるから, 補題1より, $(\mathscr{F}, m) \subseteq$ $\left(\mathscr{F}_{p}^{*}, m_{p}^{*}\right)$ となる. したがって, (26) 式より, $G(m) \geqq$ $G\left(m_{n}^{*}\right)$ が成立する。一方，(24) 式より, $G(m) \leqq$ $G\left(m_{p}^{*}\right)$ が成立する. ゆえに, $G(m)=G\left(m_{p}^{*}\right)$ ，すなわ ち，(27）式が成立する.

(証明終)

命題 1 より, 任意の証拠の体 $(\boldsymbol{I}, m)$ の巨視的な情報 測度の值は， $(\mathscr{F}, m)$ に対して定まる集合 $\boldsymbol{E}$ 内の確率 分布の巨視的な情報測度の最大值と一致する。

次の命題 2 は, (24) 式，(26）式に加えて, Lamata と Moralによってあげられた性質（ii）を満たす情報測 度が唯一であるてとを示している.

【命題 2】（24），(26）式および，性質（ii）を満たす 情報測度 $G(m)$ は,

$$
G(m)=\max _{p \in \mathcal{E}} H(p)
$$

ただ一つである.

（証明）性質（ii）を満たすためには, $G\left(m_{p}\right)=H(p)$ が成立しなければならない。乙のととと命題 1より, (28) 式は明らかである.

(証明終)

(28) 式で定義される $G(m)$ は, Lamátá と Moral があげた性質 (i ) 执よび (iii) あ満たしている. このこ とを以下で証明する.

【命題 3】（28）式で定義される $G(m)$ は，性質 (i) 拉よび性質（iii）を満たしている. 
（証明）性質（i ）は Shannon のエントロピーの性 質 ${ }^{5), 9)}$ より明らかである. 性質 (iii) を証明する.

$(\mathscr{F}, m)$ を $X \times Y$ 上の証拠の体とする. $(\mathscr{I}, m)$ の $X, Y$ への射影をそれぞれ, $\left(\mathscr{F}_{x}, m_{x}\right),\left(\mathscr{F}_{y}, m_{y}\right)$ とす ると, 性質 (iii) の仮定より, (10), (11) 式が成立する. $X=\left\{x_{1}, x_{2}, \cdots, x_{n_{x}}\right\}, Y=\left\{y_{1}, y_{2}, \cdots, y_{n_{y}}\right\},\left(\mathcal{F}_{x}, m_{x}\right)$, $\left(\mathfrak{F}_{y}, m_{y}\right)$ の焦点要素の数をそれぞれ， $\ell_{x}, \ell_{y}$ とし,

$$
\chi_{i_{x} j_{x}}=\left\{\begin{array}{l}
1 ; x_{i_{x}} \in A_{j_{x}} \\
0 ; x_{i_{x}} \notin A_{j_{x}}
\end{array}, \quad \chi_{i_{y} j_{y}}=\left\{\begin{array}{l}
1 ; y_{i_{y}} \in B_{j_{y}} \\
0 ; y_{i_{y}} \notin B_{j_{y}}
\end{array}\right.\right.
$$

とすると, $(\mathscr{I}, m),\left(\mathscr{F}_{x}, m_{x}\right),\left(\mathscr{F}_{y}, m_{y}\right)$ に対する確率 分布の集合 $\mathcal{E}, \mathcal{E}_{X}, \mathcal{E}_{Y}$ は, (10), (11) 式より,

$$
\begin{gathered}
\mathcal{E}=\left\{p=\left(p_{11}, p_{12}, \cdots, p_{1 n_{y}}, p_{21}, \cdots, p_{2 n_{y}}, \cdots,\right.\right. \\
\left.p_{n_{x} 1}, \cdots, p_{n_{x} n_{y}}\right) / p_{i_{x} i_{y}}=\sum_{j_{x}=1 j_{y}=1}^{\ell_{x}} \sum_{i_{x} j_{y}} \chi_{i_{y} j_{y}} p_{i_{x} i_{y} j_{x} j_{y}}, \\
\sum_{i_{x}=1}^{n_{x}} \sum_{i_{y}=1}^{n_{y}} \chi_{i_{x} j_{x}} \chi_{i_{y} j_{y}} p_{i_{x} i_{y} j_{x} j_{y}}=m_{x}\left(A_{j_{x}}\right) m_{y}\left(B_{j_{y}}\right), \\
p_{i_{x} i_{y} j_{x} j_{y}} \geqq 0, i_{x}=1,2, \cdots, n_{x}, i_{y}=1,2, \cdots, n_{y}, \\
\left.j_{x}=1,2, \cdots, \ell_{x}, j_{y}=1,2, \cdots, \ell_{y}\right\} \\
\mathcal{E}_{X}=\left\{q=\left(q_{1}, q_{2}, \cdots, q_{n_{x}}\right) / q_{i_{x}}=\sum_{j_{x}=1}^{\ell_{x}} \chi_{i_{x} j_{x}} q_{i_{x} j_{x}},\right. \\
\sum_{i_{x}=1}^{n_{x}} \chi_{i_{x} j_{x}} q_{i_{x} j_{x}}=m_{x}\left(A_{j_{x}}\right), q_{i_{x} j_{x}} \geqq 0, \\
\left.i_{x}=1,2, \cdots, n_{x}, j_{x}=1,2, \cdots, \ell_{x}\right\} \\
\mathcal{E}_{Y}=\left\{r=\left(r_{1}, r_{2}, \cdots, r_{n_{y}}\right) / r_{i_{y}}=\sum_{j_{y}=1}^{\ell_{y}} \chi_{i_{y} j_{y}} r_{i_{y} j_{y}},\right. \\
\sum_{i_{y}=1}^{n_{y}} \chi_{i_{y} j_{y}} r_{i_{y} j_{y}}=m_{y}\left(B_{j_{y}}\right), r_{i_{y} j_{y}} \geqq 0, \\
\left.i_{y}=1,2, \cdots, n_{y}, j_{y}=1,2, \cdots, \ell_{y}\right\}
\end{gathered}
$$

と書ける.

まず,

$$
H\left(p^{*}\right)=\max _{p \in \varepsilon} H(p)=G(m)
$$

なる $p^{*}=\left(p_{11}^{*}, p_{12}^{*}, \cdots, p_{n_{x} n_{y}}^{*}\right) \in \mathcal{E}$ を考える. $p^{*} \in \mathcal{E}$ より,

$$
\begin{aligned}
& p_{i_{x} i_{y}}^{*}=\sum_{j_{x}=1}^{\ell_{x}} \sum_{j_{y}=1}^{\ell_{y}} \chi_{i_{x} j_{x}} \chi_{i_{y} j_{y}} p_{i_{x} i_{y} j_{x} j_{y}}^{*}, \\
& \sum_{i_{x}=1}^{n_{x}} \sum_{i_{y}=1}^{n_{y}} \chi_{i_{x} j_{x}} \chi_{i_{y} j_{y}} p_{i_{x} i_{y} j_{x} j_{y}}^{*}=m_{x}\left(A_{j_{x}}\right) m_{y}\left(B_{j_{y}}\right) \\
& p_{i_{x} i_{y} j_{x} j_{y}}^{*} \geqq 0, i_{x}=1,2, \cdots, n_{x}, i_{y}=1,2, \cdots, n_{y}, \\
& j_{x}=1,2, \cdots, \ell_{x}, j_{y}=1,2, \cdots, \ell_{y} \text { ( I ) }
\end{aligned}
$$

なる $p_{i_{x} i_{y} j_{x} j_{y}}^{*}$ が存在する. $p^{*}$ の周辺分布 $q^{*}=\left(q_{1}^{*}, \cdots\right.$, $\left.q_{n_{x}}^{*}\right), r^{*}=\left(r_{1}^{*}, \cdots, r_{n_{y}}^{*}\right)$ を考える亡, Shannon のエ ントロピーの性質 ${ }^{5), 9)}$ より,

$$
G(m)=H\left(p^{*}\right) \leqq H\left(q^{*}\right)+H\left(r^{*}\right)
$$

となる.

ここで, $q^{*} \in \mathcal{E}_{X}$ を示す.（I）の第一式より,

$$
q_{i_{x}}^{*}=\sum_{i_{y}=1}^{n_{y}} p_{i_{x} i_{y}}^{*}=\sum_{j_{x}=1}^{\ell_{x}} \chi_{i_{x} j_{x}}\left(\sum_{i_{y}=1}^{n_{y}} \sum_{j_{y}=1}^{\ell_{y}} \chi_{i_{y} j_{y}} p_{i_{x} i_{y} j_{x} j_{y}}^{*}\right)
$$

と書ける.（I ）の第二式より,

$$
\begin{aligned}
& \sum_{i_{x}=1}^{n_{x}} \chi_{i_{x} j_{x}}\left(\sum_{i_{y}=1}^{n_{y}} \sum_{j_{y}=1}^{\ell_{y}} \chi_{i_{y} j_{y}} p_{i_{x} i_{y} j_{x} j_{y}}^{*}\right) \\
& =m_{x}\left(A_{j_{x}}\right) \sum_{j_{y}=1}^{\ell_{y}} m_{y}\left(B_{j_{y}}\right)=m_{x}\left(A_{j_{x}}\right)
\end{aligned}
$$

となり, $q_{i_{x} j_{x}}^{*}=\left(\sum_{i_{y}=1}^{n_{y}} \sum_{j_{y}=1}^{\ell_{y}} \chi_{i_{y} j_{y}} p_{i_{x} i_{y} j_{x} j_{y}}^{*}\right)$ とすると, ( I ) の第三式より， $q_{i_{x} j_{x}}^{*} \geqq 0$ となる. ゆえに, $q^{*} \in \mathcal{E}_{X}$ と なる. 同様に, $r^{*} \in \mathcal{E}_{Y}$ あ証明できる.

$$
\begin{aligned}
q^{*} & \in \mathcal{E}_{X}, r^{*} \in \mathcal{E}_{Y} \text { より, } \\
H\left(q^{*}\right) & \leqq \max _{q \in \mathcal{E}_{X}} H(q)=G\left(m_{x}\right) \\
H\left(r^{*}\right) & \leqq \max _{r \in \varepsilon_{Y}} H(r)=G\left(m_{y}\right)
\end{aligned}
$$

となり,（II）より, 次式が成立する.

$$
G(m) \leqq G\left(m_{x}\right)+G\left(m_{y}\right)
$$

逆に,

$$
\begin{aligned}
& H\left(q^{0}\right)=\max _{q \Subset \varepsilon_{X}} H(q)=G\left(m_{x}\right) \\
& H\left(r^{0}\right)=\max _{r \in \varepsilon_{Y}} H(r)=G\left(m_{y}\right)
\end{aligned}
$$

なる $q^{0}=\left(q_{1}^{0}, \cdots, q_{n_{x}}^{0}\right) \in \mathcal{E}_{X}, r^{0}=\left(r_{1}^{0}, \cdots, r_{n_{y}}^{0}\right) \in \mathcal{E}_{Y}$ を 考える. $q^{0} \in \mathcal{E}_{X}, r^{0} \in \mathcal{E}_{Y}$ より，

$$
\begin{aligned}
& q_{i_{x}}^{0}=\sum_{j_{x}=1}^{\ell_{x}} \chi_{i_{x} j_{x}} q_{i_{x} j_{x}}^{0}, \sum_{i_{x}=1}^{n_{x}} \chi_{i_{x} j_{x}} q_{i_{x} j_{x}}^{0}=m_{x}\left(A_{j_{x}}\right), \\
& q_{i_{x} j_{x}}^{0} \geqq 0, i_{x}=1,2, \cdots, n_{x}, j_{x}=1,2, \cdots, \ell_{x} \\
& r_{i_{y}}^{0}=\sum_{j_{y}=1}^{\ell_{y}} \chi_{i_{y} j_{y}} r_{i_{y} j_{y}}^{0}, \sum_{i_{y}=1}^{n_{y}} \chi_{i_{y} j_{y}} r_{i_{y} j_{y}}^{0}=m_{y}\left(B_{j_{y}}\right), \\
& r_{i_{y} j_{y}}^{0} \geqq 0, i_{y}=1,2, \cdots, n_{y}, j_{y}=1,2, \cdots, \ell_{y}
\end{aligned}
$$

なる $q_{i_{x} j_{x}}^{0}, r_{i_{y} j_{y}}^{0}$ が存在する. $q^{0}, r^{0}$ が独立であると仮 定し, 同時分布 $p^{0}=\left(p_{11}^{0}, p_{12}^{0}, \cdots \cdots, p_{n_{x} n_{y}}^{0}\right)$ を

$$
p_{i_{x} i_{y}}^{0}=q_{i_{x}}^{0} r_{i_{y}}^{0}
$$

により構成すると, Shannon のエントロピーの性質 ${ }^{5), 9)}$ より，次式が成立する.

$$
H\left(p^{0}\right)=H\left(q^{0}\right)+H\left(r^{0}\right)=G\left(m_{x}\right)+G\left(m_{y}\right)
$$

ここで, $p^{0} \in \mathcal{E}$ を示す. (IV), (V) の第一式より,

$$
p_{i_{x} i_{y}}^{0}=\sum_{j_{x}=1}^{\ell_{x}} \sum_{j_{y}=1}^{\ell_{y}} \chi_{i_{x} j_{x}} \chi_{i_{y} j_{y}} q_{i_{x} j_{x}}^{0} r_{i_{y} j_{y}}^{0}
$$

と書ける. また, (IV), (V)の第二式より,

$$
\sum_{i_{x}=1}^{n_{x}} \sum_{i_{y}=1}^{n_{y}} \chi_{i_{x} j_{x}} \chi_{i_{y} j_{y}} q_{i_{x} j_{x}}^{0} r_{i_{y} j_{y}}^{0}=m_{x}\left(A_{j_{x}}\right) m_{y}\left(B_{j_{y}}\right)
$$

となり, $p_{i_{x} i_{y} j_{x} j_{y}}^{0}=q_{i_{x} j_{x}}^{0} r_{i_{y} j_{y}}^{0}$ とすると, $p_{i_{x} i_{y} j_{x} j_{y}}^{0} \geqq 0$ と 
なる。ゆえに， $p^{0} \in \mathcal{E}$ が成立する。

$$
p^{0} \in \mathcal{E} よ り,
$$

$$
H\left(p^{0}\right) \leqq \max _{p \in \mathcal{E}} H(p)=G(m)
$$

となり，（VI）より，次式が成立する.

$$
G(m) \geqq G\left(m_{x}\right)+G\left(m_{y}\right)
$$

したがって，（III），(VII）より，次式が成立す る.

$$
G(m)=G\left(m_{x}\right)+G\left(m_{y}\right)
$$

命題 2，3 より，(28）式で定義される $G(m)$ は，性質（i ）（iii），(iv') のすべてを満たす 唯一の情報測度であるととがわかる。

結局，(28）式より明らかなように，(24）, （26）式扔よび性質（ii）を満たす巨視的な情報 測度は, 証拠の体 $(\boldsymbol{F}, m)$ を確率分布の集合 $\boldsymbol{E}$ と考えたときの ampliative reasoning ${ }^{5}$, つまり，エントロピー最大化に基づいて定めら れる確率分布のエントロピーに一致する.

\section{4. 簡単な実験による考察}

\section{1 実験の目的}

巨視的な情報測度は「人間が考える（感じる） 系の全体的な不明確さはどのようなあのである か」という根拠にできるだけ即している方が望 ましいと考えられる.

本章では，被験者が一対の証拠の体における 全体的な不明確さを比較する実験を行ない, 下界エントロピー $L(m)$, 上界エントロピー $U(m)$, 打よび, 本提案の巨視的な情報測度 $G(m)$ のいずれが，人間の考える系の全体的 な不明確さをうまく表現しているかを調べる.

\section{2 実験方法および実験結果}

実験では，全体集合 $X$ の濃度 $|X|=n$ が 2 4 のそれぞれについて 10 種の証拠の体 $(\mathscr{F}, m)$ を構成し，そのイメージを描いた. Fig. 1〜3 の試料を用いた. Fig. 1〜3では, 各 $(\mathscr{I}, m)$ を 区別するため，試料の左上に名称を付けている. たとえば，Fig.1の 2-2 の試料は $m\left(\left\{x_{1}\right\}\right)=$ $1 / 4, m\left(\left\{x_{2}\right\}\right)=3 / 4$ なる $(\mathscr{F}, m)$ をを描いてお り, Fig.2の 3-4 の試料は $m\left(\left\{x_{1}, x_{2}, x_{3}\right\}\right)=$ $1 / 2, m\left(\left\{x_{2}, x_{3}\right\}\right)=1 / 2$ なる $(\mathscr{F}, m)$ を描い ている.ほかす同様である．試料として用いた それぞれの $(\mathscr{F}, m)$ から算出した $L(m)$, $U(m), G(m)$ の值を Table 1〜3 亿示す.

これらの試料を用いて, 次のような実験を行

\begin{tabular}{|c|c|c|c|c|}
\hline $\begin{array}{l}\frac{3-1}{*} * \\
\frac{0}{0} \\
\frac{1}{2} \frac{0}{\frac{1}{2}}\end{array}$ & 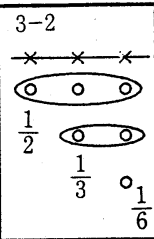 & $\begin{array}{llll}3-3 & & \\
* & * & * \\
0 & 0 & 0 \\
\frac{1}{6} & 6 & 0 \\
& \frac{1}{3} & 0 \\
& & \frac{1}{2}\end{array}$ & 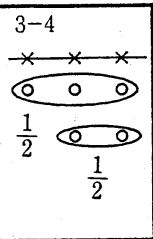 & 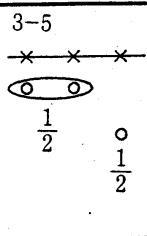 \\
\hline $\begin{array}{cccc}3-6 & & \\
* & * & * \\
0 & 0 & 0 \\
0 & 0 & \frac{1}{2} \\
1 & & \end{array}$ & 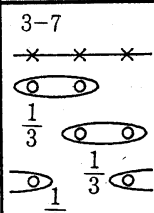 & 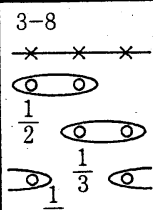 & $\begin{array}{lll}3-9 & & \\
* & * & * \\
\sigma & 0 & \\
\frac{1}{2} & \varnothing & 0 \\
0 & \frac{1}{4} & \sigma\end{array}$ & $\begin{array}{ll}3-10 & \\
* & * \\
\circ & \\
\frac{1}{6} & \circ \\
& 1\end{array}$ \\
\hline
\end{tabular}

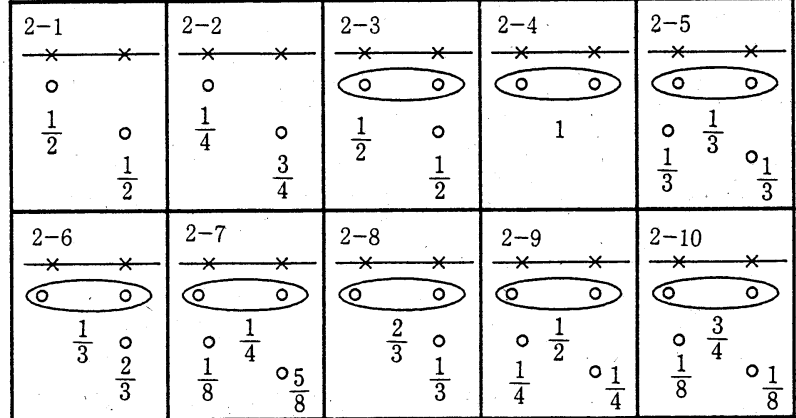

Fig. 1 Bodies of evidence used in the experiment in the case of $n=2$

\begin{tabular}{|c|c|c|c|c|}
\hline $\begin{array}{c}4-1 \\
* * * * * \\
\odot \odot \\
\frac{1}{3} \odot 0 \\
\frac{1}{3} \odot 0 \\
\frac{1}{3}\end{array}$ & 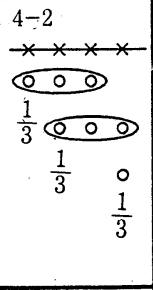 & $\begin{array}{c}4-3 \\
* x-x-x \\
000 \\
\frac{1}{4} \odot 00 \\
0 \frac{1}{4} \\
\frac{00}{\frac{1}{4}}\end{array}$ & 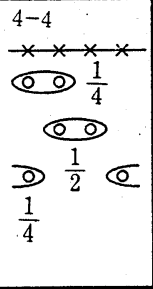 & $\begin{array}{lll}4-5 & \\
* & * x-x \\
\circ & & \\
\frac{1}{6} & 0 & \\
& \frac{1}{3} & \\
& \circ & \\
& \frac{1}{3} & \circ \\
& & \frac{1}{6}\end{array}$ \\
\hline $\begin{array}{l}4-6 \\
\frac{*}{*} * * * * \\
\frac{0}{0} 000 \\
\frac{2}{3} \odot 0 \\
\frac{1}{3}\end{array}$ & 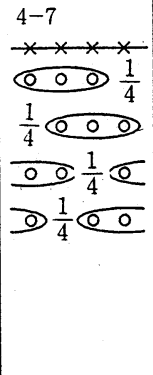 & 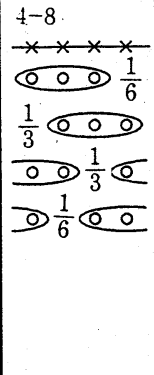 & 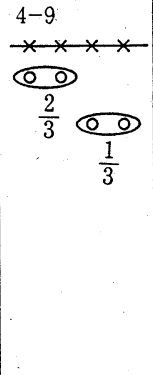 & 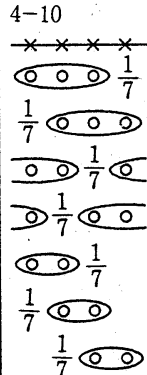 \\
\hline
\end{tabular}

Fig. 2 Bodies of evidence used in the experiment in the case of $n=3$

Fig. 3 Bodies of evidence used in the experiment in the case of $n=4$ 
Table 1 The values of $G(m), L(m)$ and $U(m)$ in the case of $n=2$

\begin{tabular}{c|c|c|c}
\hline$(\boldsymbol{F}, m)$ & $L(m)$ & $U(m)$ & $G(m)$ \\
\hline $2-1$ & 1.00 & 1.00 & 1.00 \\
\hline $2-2$ & 0.81 & 0.81 & 0.81 \\
\hline $2-3$ & 0.50 & 0.58 & 1.00 \\
\hline $2-4$ & 1.00 & 1.00 & 1.00 \\
\hline $2-5$ & 0.72 & 1.00 & 1.00 \\
\hline $2-6$ & 0.33 & 0.42 & 0.92 \\
\hline $2-7$ & 0.55 & 0.67 & 0.95 \\
\hline $2-8$ & 0.67 & 0.74 & 1.00 \\
\hline $2-9$ & 0.71 & 1.00 & 1.00 \\
\hline $2-10$ & 0.80 & 1.00 & 1.00 \\
\hline
\end{tabular}

Table 2 The values of $G(m), L(m)$ and $U(m)$ in the case of $n=3$

\begin{tabular}{c|c|c|c}
\hline$(\mathcal{I}, m)$ & $L(m)$ & $U(m)$ & $G(m)$ \\
\hline $3-1$ & 1.00 & 1.00 & 1.58 \\
\hline $3-2$ & 1.13 & 1.22 & 0.58 \\
\hline $3-3$ & 0.60 & 0.74 & 1.46 \\
\hline $3-4$ & 1.29 & 1.32 & 1.58 \\
\hline $3-5$ & 1.50 & 1.58 & 1.50 \\
\hline $3-6$ & 1.29 & 1.32 & 1.58 \\
\hline $3-7$ & 1.00 & 1.58 & 1.58 \\
\hline $3-8$ & 1.00 & 1.32 & 1.58 \\
\hline $3-9$ & 1.00 & 1.42 & 1.58 \\
\hline $3-10$ & 1.46 & 1.46 & 1.46 \\
\hline
\end{tabular}

Table 3 The values of $G(m), L(m)$ and $U(m)$ in the case of $n=4$

\begin{tabular}{c|c|c|c}
\hline$(\boldsymbol{F}, m)$ & $L(m)$ & $U(m)$ & $G(m)$ \\
\hline $4-1$ & 1.39 & 1.58 & 2.00 \\
\hline $4-2$ & 1.45 & 1.81 & 1.97 \\
\hline $4-3$ & 1.50 & 1.74 & 2.00 \\
\hline $4-4$ & 1.46 & 1.56 & 2.00 \\
\hline $4-5$ & 1.92 & 1.92 & 1.92 \\
\hline $4-6$ & 1.67 & 1.74 & 2.00 \\
\hline $4-7$ & 1.58 & 2.00 & 2.00 \\
\hline $4-8$ & 1.58 & 1.85 & 2.00 \\
\hline $4-9$ & 1.92 & 1.92 & 1.92 \\
\hline $4-10$ & 1.39 & 1.85 & 2.00 \\
\hline
\end{tabular}

なった。試料に描かれている $(\mathscr{F}, m)$ を説明した後, 各被験者に $n=2 \sim 4$ のそれぞれについて, 10 種の $(\boldsymbol{I}, m)$ のすべての対（45 対）の全体的な不明確さを 比較させた。 なお, 解答形式は「○○○の方が不明確 である」あるいは「両者とあ不明確さは同じである」の 二つに限定した. 比較する対の順序は乱数を用いてラン ダムにし, 被験者ごとに比較する対の順序が異なるよう にした. 被験者は, 18 歳から 25 歳までの男性 10 人で あった。

実験の結果を Table 4～6 に示す. Table 4～6 では, 行の $(\mathfrak{F}, m)$ の方が列の $(\mathfrak{F}, m)$ 上り不明確であると 答えた人数を表わしている. たとえば, Table 4 の 2-2 の行，2-3、列に拈り 1 は， 10 人中 1 人が「2-2の 方が 2-3 より不明確である」と答えたことを示してい る. なお， 2-2 行 2-3 列と 2-3 行. 2-2 列の数值の和 が 10 に満たないのは，「両者の不明確さが同じである」 と答えた人が $3(=10-1-6)$ 人いるととを示している.

つぎに, Table 1〜3の $L(m), U(m), G(m)$ と Table 4〜6 の得られた結果を利用して, $L(m), U(m)$, $G(m)$ それぞれの数值による比較と一致している人数 の平均, 分散, メジアン, 最小值, 最大值を Table 7 に示す. ここで, $G(m)$ による比較と一致するとは, $\left(\mathscr{F}_{1}, m_{1}\right),\left(\mathscr{F}_{2}, m_{2}\right)$ について $G\left(m_{1}\right)>G\left(m_{2}\right)$ のと き, 被験者が $\left(\mathscr{F}_{1}, m_{1}\right)$ を $\left(\mathscr{F}_{2}, m_{2}\right)$ より不明確であると 答え, $G\left(m_{1}\right)=G\left(m_{2}\right)$ のとき, $\left(\mathscr{F}_{1}, m_{1}\right)$ と $\left(\mathscr{F}_{2}, m_{2}\right)$ の不明確さが同じであると答えることをいう. $L(m)$, $U(m)$ についてあ同様である. また, $L(m), U(m)$, $G(m)$ それぞれの数値による比較のうち，厳密な不等号 関係>が成立する対のみについて，その比較結果に一 致して答えている被験者数の平均, 分散, メジアン, 最 小值, 最大值を Table 8 に示す.さらに, Table 9 で は, $L(m), U(m), G(m)$ それぞれの数值による比較 のうち，厳密な不等号関係>が成立する対について， その比較結果と逆転する（逆の不等号を指示する）被験 者数の平均, 分散, メジアン, 最小値, 最大值を示して いる.

\section{3 考 察}

Table 7 の結果から, $U(m)$ による比較と人間によ る比較が一致している人数の平均, メジアンが最も大き く, 分散も比較的小さいので, $U(m)$ による比較が人間 による比較に最む近いと推測される。 しかし, Table 9 に示すように, $U(m)$ による比較と人間による比較が逆 転している人数の平均, メジアン, 最大值が $G(m)$ の それらよりあ大きい. とくに, $n=2,4$ における $U(m)$ による比較では, 最大值が 10 であり, 被験者全員が $U(m)$ による比較結果と逆転する場合がある. $2-2$ 之 
Table 4 Data gathered from the experiment in the case of $n=2$

\begin{tabular}{|c|c|c|c|c|c|c|c|c|c|c|}
\hline & $2-1$ & $2-2$ & $2-3$ & $2-4$ & $2-5$ & $2-6$ & $2-7$ & $2-8$ & $2-9$ & $2-10$ \\
\hline $2-1$ & & 10 & 9 & 4 & 4 & 10 & 10 & 8 & 1 & 4 \\
\hline $2-2$ & 0 & & 1 & 0 & 0 & 3 & 1 & 0 & 0 & 1 \\
\hline $2-3$ & 1 & 6 & & 3 & 0 & 10 & 4 & 2 & 0 & 0 \\
\hline $2-4$ & 2 & 10 & 7 & & 4 & 8 & 5 & 7 & 3 & 3 \\
\hline $2-5$ & 2 & 9 & 10 & 2 & & 10 & 10 & 8 & 1 & 2 \\
\hline $2-6$ & 0 & 6 & 0 & 3 & 0 & & 1 & 0 & 0 & 0 \\
\hline $2-7$ & 1 & 4 & 4 & 4 & 0 & 9 & & & 0 & 0 \\
\hline $2-8$ & 2 & 10 & 7 & 3 & 2 & 8 & 5 & & 1 & 1 \\
\hline $2-9$ & 4 & 9 & 10 & 4 & 6 & 10 & 9 & 9 & & 0 \\
\hline $2-10$ & 3 & 9 & 10 & 4 & 4 & 10 & 8 & 9 & 5 & \\
\hline
\end{tabular}

Table 5 Data gathered from the experiment in the case of $n=3$

\begin{tabular}{|c|c|c|c|c|c|c|c|c|c|c|}
\hline & $3-1$ & $3-2$ & $3-3$ & $3-4$ & $3-5$ & $3-6$ & $3-7$ & $3-8$ & $3-9$ & $3-10$ \\
\hline $3-1$ & & 8 & 10 & 3 & 7 & 5 & 2 & 2 & 2 & 9 \\
\hline $3-2$ & 2 & & 8 & 2 & 6 & 0 & 0 & 3 & 1 & 6 \\
\hline $3-3$ & 0 & 1 & & 0 & 3 & 0 & 0 & 1 & 0 & 3 \\
\hline $3-4$ & 7 & 8 & 10 & & 6 & 4 & 1 & 5 & 3 & 7 \\
\hline $3-5$ & 1 & 4 & 7 & 4 & & 4 & 1 & 3 & 1 & 9 \\
\hline $3-6$ & 5 & 10 & 10 & 6 & 6 & & 1 & 6 & 2 & 8 \\
\hline $3-7$ & 7 & 10 & 10 & 9 & 9 & 9 & & 8 & 8 & 9 \\
\hline $3-8$ & 8 & 5 & 9 & 4 & 7 & 4 & 1 & & 1 & 8 \\
\hline $3-9$ & 7 & 9 & 10 & 7 & 8 & 8 & 1 & 7 & & 6 \\
\hline $3-10$ & 1 & 1 & 7 & 3 & 1 & 2 & 1 & 1 & 4 & \\
\hline
\end{tabular}

Table 6 Data gathered from the experiment in the case of $n=4$

\begin{tabular}{|c|c|c|c|c|c|c|c|c|c|c|}
\hline & $4-1$ & $4-2$ & $4-3$ & $4-4$ & $4-5$ & $4-6$ & $4-7$ & $4-8$ & $4-9$ & $4-10$ \\
\hline $4-1$ & & 10 & 5 & 8 & 5 & 5 & 1 & 5 & 8 & 0 \\
\hline $4-2$ & 0 & & 1 & 3 & 7 & 2 & 1 & 2 & 3 & 1 \\
\hline $4-3$ & 5 & 9 & & 10 & 7 & 6 & 2 & 4 & 7 & 1 \\
\hline $4-4$ & 1 & 6 & 0 & & 4 & 3 & 1 & 2 & 7 & 0 \\
\hline $4-5$ & 1 & 3 & 2 & 6 & & 2 & 1 & 2 & 4 & 1 \\
\hline $4-6$ & 3 & 8 & 2 & 7 & 4 & & 0 & 1 & 6 & 0 \\
\hline $4-7$ & 8 & 9 & 8 & 9 & 9 & 10 & & 7 & 9 & 6 \\
\hline $4-8$ & 4 & 8 & 6 & 8 & 6 & 8 & 2 & & 8 & 2 \\
\hline $4-9$ & 2 & 7 & 2 & 3 & 3 & 3 & 1 & 2 & & 1 \\
\hline $4-10$ & 8 & 9 & 9 & 10 & 8 & 9 & 4 & 8 & 9 & \\
\hline
\end{tabular}

Table 7 Data about the number of persons agreed on the result based on each global information measure

\begin{tabular}{c|c|c|c|c|c|c}
\hline & & mean & variance & median & $\begin{array}{c}\text { minimum } \\
\text { value }\end{array}$ & $\begin{array}{c}\text { maximum } \\
\text { value }\end{array}$ \\
\hline \multirow{4}{*}{$n=2$} & $L(m)$ & 6.200 & 12.116 & 7 & 0 & 10 \\
\cline { 2 - 7 } & $U(m)$ & 6.667 & 9.822 & 8 & 0 & 10 \\
\cline { 2 - 7 } & $G(m)$ & 5.289 & 14.294 & 5 & 0 & 10 \\
\hline \multirow{3}{*}{$n=3$} & $L(m)$ & 4.089 & 11.725 & 3 & 0 & 10 \\
\cline { 2 - 7 } & $U(m)$ & 5.844 & 11.598 & 7 & 0 & 10 \\
\cline { 2 - 7 } & $G(m)$ & 4.311 & 15.859 & 6 & 0 & 10 \\
\hline \multirow{3}{*}{$n=4$} & $L(m)$ & 3.711 & 9.272 & 2 & 0 & 10 \\
\cline { 2 - 7 } & $U(m)$ & 5.222 & 10.528 & 6 & 0 & 10 \\
\cline { 2 - 7 } & $G(m)$ & 4.222 & 12.973 & 4 & 0 & 10 \\
\hline
\end{tabular}

Table 8 Data about the number of persons agreed on the result based on each global information measure when strict inequality holds

\begin{tabular}{c|c|c|c|c|c|c}
\hline & & mean & variance & median & $\begin{array}{c}\text { minimum } \\
\text { value }\end{array}$ & $\begin{array}{c}\text { maximum } \\
\text { value }\end{array}$ \\
\hline \multirow{4}{*}{$n=2$} & $L(m)$ & 6.250 & 12.278 & 7.5 & 0 & 10 \\
\cline { 2 - 7 } & $U(m)$ & 7.771 & 7.948 & 9 & 0 & 10 \\
\cline { 2 - 7 } & $G(m)$ & 8.292 & 4.207 & 9 & 4 & 10 \\
\hline \multirow{5}{*}{$n=3$} & $L(m)$ & 4.605 & 11.555 & 4 & 0 & 10 \\
\cline { 2 - 7 } & $U(m)$ & 6.390 & 9.360 & 7 & 1 & 10 \\
\cline { 2 - 7 } & $G(m)$ & 8.043 & 2.129 & 8 & 6 & 10 \\
\hline \multirow{5}{*}{$n=4$} & $L(m)$ & 3.905 & 9.753 & 2.5 & 0 & 10 \\
\cline { 2 - 7 } & $U(m)$ & 5.452 & 9.962 & 6 & 0 & 10 \\
\cline { 2 - 7 } & $G(m)$ & 7.217 & 3.388 & 8 & 3 & 10 \\
\hline
\end{tabular}

Table 9 Data about the number of persons against the result based on each global information measure when strict inequality holds

\begin{tabular}{l|c|c|c|c|c|c}
\hline & & mean & variance & median & $\begin{array}{c}\text { minimum } \\
\text { value }\end{array}$ & $\begin{array}{c}\text { maximum } \\
\text { value }\end{array}$ \\
\hline \multirow{3}{*}{$n=2$} & $L(m)$ & 2.659 & 8.225 & 2 & 0 & 10 \\
\cline { 2 - 7 } & $U(m)$ & 1.686 & 5.187 & 1 & 0 & 10 \\
\hline \multirow{3}{*}{$n=3$} & $G(m)$ & 0.958 & 2.040 & 0 & 0 & 4 \\
\cline { 2 - 7 } & $L(m)$ & 5.105 & 10.726 & 6 & 0 & 10 \\
\cline { 2 - 7 } & $U(m)$ & 3.220 & 8.269 & 2 & 0 & 9 \\
\hline \multirow{3}{*}{$n=4$} & $L(m)$ & 1.609 & 1.977 & 1 & 0 & 4 \\
\cline { 2 - 7 } & $U(m)$ & 5.452 & 8.676 & 5.5 & 0 & 10 \\
\cline { 2 - 7 } & & 3.976 & 8.785 & 4 & 0 & 10 \\
\hline
\end{tabular}


2-8 の対，4-1 と 4-2 の対などはその例である.した がって, $U(m)$ による比較は人間による比較と完全に 逆転する場合があり，乙の意味で健全であるとはいえな い.

一方, $G(m)$ による比較は, Table 7 より，人間に よる比較と一致している人数の平均, メジアンが小さい ので, この結果から， $G(m)$ が最適であるとはいえな い.しかし, Table 7 の $G(m)$ の平均, メジアンが小 さいのは, $G(m)$ による比較において等号が成立する 対が多いためと考えられる. 実際, Table 8 をみると, $G(m)$ による比較が人間による比較に最む一致してい る. さらに, Table 9 により, $G(m)$ による比較と人間 による比較が逆転している人数の平均, メジアン, 最大 值が最む小さく, $L(m), U(m)$ に比べて健全であると いえる.

$L(m)$ による比較は, Table 7〜9 のいずれにおいて あ $G(m)$ あるいは $U(m)$ に劣り, $G(m), U(m)$ ほど 人間による比較に一致しない.

以上の考察より，厳密な不等号関係が成立する場合， $G(m)$ による比較が人間による比較に最も一致し，し かむ，逆転する人数の平均，メジアンが小さく，最す健 全であるといえる:

\section{5. おわりに}

証拠理論において，系自体に内在する不明確さと，系， に対する人間の知識，情報における不明確さが取り扱わ れているという観点から，系自体の不明確さを表わす情 報測度が満たすべき性質, 人間の知識, 情報の不明確さ を表わす情報測度が満たすべき性質を考え，両方の性質 を満たす巨視的な情報測度を提案した．すなわち，系自 体の不明確さを表わすための性質，人間の知識，情報の 不明確さを表わすための性質の両方を満たし，しかも， Shannonのエントロピーの拡張であるためには,

$$
G(m)=\max _{p \in \mathcal{E}} H(p)
$$

でなければならないことを示した，さらに，本提案の 巨視的な情報測度 $G(m)$ と Lamata と Moral による 巨視的な情報測度 $L(m), U(m)$ のいずれが，人間の考 える（感じる）全体的な不明確さを表現しているかを調 べるため，簡単な実験を行なった. その結果, $G(m)$,

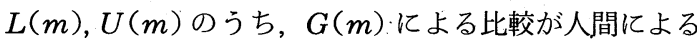
比較との逆転が最む少なく，健全であるてとが判明した，

なお，提案された $G(m)$ の值を求めるためには，凹 計画問題を解く必要があり, $E(m), C(m), V(m)$, $L(m), U(m)$ の值の算出に比へ困難である. 簡便な $G(m)$ の値の計算方法の考案などが今後の課題である.

\section{参 考 文 献}

1) D. Dubois and H. Prade : Fuzzy Sets and Systems : Theory and Applications, Academic Press (1980)

2) D. Dubois and H. Prade : Possibility Theory, Plenum Press (1988)

3) A. P. Dempster : Upper and Lower Probabilities Induced by a Multivalued Mapping ; Annals of Mathematical Statistics, Vol. 38, pp. 325 339 (1967)

4) G. Shafer : A Mathematical Theory of Evidence, Princeton Univ. Press (1976)

5) G. J. Klir and T. A. Folger : Fuzzy Sets, Uncertainty, and Information, Prentice Hall (1988)

6) G. J. Klir : Where Do We Stand on Measures of Uncertainty, Ambiguity Fuzziness, and the Like? ; Fuzzy Sets and Syst., Vol. 24, pp. 141 160 (1987)

7) D. Dubois and H. Prade : Properties of Measures of Information in Evidence and Possibility Theories ; Fuzzy Sets and Syst., Vol. 24, pp.161 182 (1987)

8) M. T. Lamata and S. Moral : Measures of Entropy in the Theory of Evidence ; Int. J. General Systems, Vol. 14, pp. 297 305 (1987)

9）国沢 : 情報理論 $I$ ーエントロピーと情報量一, 共立出版 (1983)

10) M. Delgado and S. Moral : A Definition of Inclusion for Evidences ; 模糊数学, Vol. 7, No. 1, pp, 81 87 (1987)

11) D. Dubois and H. Prade : A Set-Theoretic View of Belief Functions : Logical Operations and Approximations by Fuzzy Sets ; Int. J. General Systems, Vol. 12, pp. 193 226 (1986) 